\title{
A MERCANTILIZAÇÃO DO ENSINO SUPERIOR BRASILEIRO: AS CONTRADIÇÕES E OS AVANÇOS POSSÍVEIS NA REALIDADE CEARENSE
}

\author{
Karine PINHeIRO de Souza \\ Universidade de Aveiro (UA), Aveiro, Portugal \\ Nayana Lima Santos \\ Universidade Estadual do Ceará (UECE), Fortaleza, Ceará, Brasil \\ Rafael dos Santos da Silva \\ Universidade Federal do Ceará (UFC), Fortaleza, Ceará, Brasil
}

\begin{abstract}
Resumo: Ao discutir o cenário do financiamento da educação superior no Brasil, o presente artigo recorre a leituras intrigantes referentes às chamadas políticas afirmativas de financiamento do ensino superior. Com o objetivo de analisar o fenômeno da mercantilização do Ensino Superior Brasileiro no contexto de políticas afirmativas, nomeadamente o Fundo de Financiamento Estudantil - FIES e Programa Universidade para Todos - PROUNI, o estudo apresenta inicialmente um breve resgate histórico da relação da educação como direito e as tentativas de utilizá-la como mercadoria. Em seguida, o trabalho se vale de uma pesquisa de campo qualitativa, a partir do estudo de caso desenvolvido com alunos do Serviço Social, matriculados em uma IES privada, localizada no município de Icó, Sertão central do Ceará. Foi desenvolvida uma análise de conteúdo, com base nos dados das entrevistas, em que observou-se o forte impacto de tais políticas no âmbito mercadológico, chamando atenção ao forte caráter de privatização estabelecido ao ensino superior brasileiro no sertão central do Ceará.
\end{abstract}

Palavras-chave: Financiamento da educação. Mercantilização. FIES. PROUNI.

\section{EDUCAÇÃO SUPERIOR A DISPUTA ENTRE O PÚBLICO E PRIVADO}

Quando a educação, principalmente relacionada ao Ensino Superior, desponta como um mercado em potencial, órgãos internacionais findam por intermediar em sua regulamentação e orientação, para que haja bom desempenho do mercado para a determinada área. Assim, o Banco Internacional para a Reconstrução e Desenvolvimento - BIRD tem interferido no campo da educação superior nos últimos anos, apresentando orientações para execução e desenvolvimento da política educacional. Esse processo de 
monstra tendência de privatização do ensino público, sendo regulamentado por órgãos externos e legalizado no Brasil, através das alterações de legislações, indicando clara transformação da educação em mercadoria, com a justificativa de redução de gastos públicos. Compreende-se que a chamada universalização da educação alcança novos patamares, completamente adaptados aos padrões do neoliberalismo. Um exemplo disso é a massificação da modalidade de ensino à distância, em todos os níveis de educação. No que tange ao acesso, a ampliação ocorreu em todas as classes sociais, por meio de financiamentos e bolsas de estudo, possibilitando o acesso de estudantes de classes sociais menos favorecidas a instituições privadas de ensino superior, como estratégia de ampliação da Educação. Esta categórica, mecânica e metódica estratégia de expansão da educação, se inicia na década de 60 , mas avança e se consolida com o neoliberalismo dos anos 90. O sociólogo da Educação, Licínio Lima (2012), aponta uma reflexão sobre a essência da educação enquanto direito humano contrária a fenômenos como "adestramento, endoutrinamento ou condicionamento dos seres humanos". A questão não é somente massificar o acesso para condicionar a um mercado de trabalho voltado a um processo de educação bancária, sem repensar nossos processos formativos para que os estudantes possam compreender os desafios sociais que estão inseridos e, assim, formarem-se como cidadãos críticos e participativos (Freire, 1982).

Os elementos acima remetem à precarização da educação, transformada em mercadoria, a partir da expansão do ensino superior privado, que passa a assumir as características de simples objeto pela comercialização da educação - gerando um mercado de compra e venda de diplomas. Para Bittar (2010), esse processo vem sendo consolidado na educação superior, o que permite ao autor questionar a qualidade dessa "mercadoria" chamada educação, na reprodução da realidade. É a partir desse contexto que Aued $(2015$, p. 17) vai sustentar que: "As universidades expressam essa realidade produtiva do nosso tempo, tempo do capital se autoproduzindo em processo contraditório".

Na lógica do processo civilizatório para o capital, as universidades acabam por se tornarem instrumento desta produção e reprodução material, completamente adaptadas às velhas e novas necessidades do capital e do mercado, relegando a segundo plano a formação cidadã, autônoma e emancipatória. Percebe-se um completo amoldamento das graduações para tais necessidades mercadológicas, por exemplo, a revisão dos currículos para a diminuição dos tempos dos cursos. Fala-se, então, de educação para empregabilidade (LIMA, 2012), apontando o indivíduo como responsável direto das suas oportunidades de entrada no mercado de trabalho. Assim, a educação também passa a fazer parte dessa lógica individualista e da responsabilidade específica, característica essa que reforça o papel mínimo do Estado, responsabilizando os indivíduos pelas suas mazelas e insucessos.

Esse mecanismo conduz o processo de exclusão no Ensino Superior, o que implica ações afirmativas como solução. As políticas de inclusão afirmativas são necessárias em razão da existência de sistemas segregacionistas. Sociedades que apresentam extremas desigualdades sociais, findam por limitar de forma alarmante o acesso/permanência dos cidadãos no ensino superior. 
SOUZA, K. P. de; SANTOS, N. L.; SILVA, R. dos S. da

Uma das políticas afirmativas é traduzida por políticas de cotas, associadas aos programas sociais voltados para bolsas de estudos e financiamentos estudantis. Hoje, materializam-se no país através de programas como PROUNI (Programa Universidade para Todos) e FIES (Fundo de Financiamento Estudantil). Tais programas proporcionaram mudança na ocupação de vagas em instituições de ensino superior brasileiro. Políticas de ações afirmativas, são, antes de tudo, políticas de caráter compensatório, podendo resolver o problema em sua aparência, mas não em sua essência. Os impactos são apenas superficiais nas problemáticas e nas expressões das questões sociais que se propõem a solucionar. Silva (2010) observa que as políticas compensatórias apontam ações dos governos para minorar os efeitos das desigualdades sociais nos estratos populacionais menos favorecidos. A autora afirma que as ações afirmativas proporcionam resgate do tempo perdido. Porém, há de se questionar sempre a inversão de investimentos e as parcerias, cada vez mais valorizadas entre público/privado. É no uso dessas estratégias que a educação é transformada em mercadoria. Para compreender essa abordagem é necessário, primeiro, discutir o processo de mercantilização e privatização do ensino superior, e, associado a isso, o desmonte e sucateamento das IES públicas.

\section{UM RESUMO DO NEGOCIO DA EDUCAÇÃO SUPERIOR NO BRASIL}

A reflexão sobre a isenção do Estado, no tocante à garantia da educação pública e de qualidade para todos, é seguida por políticas seletivas. Por guardarem essas características, elas promoverão a autonomia da educação, na qual degrada e desvalorizase o público e supervaloriza o privado, tornando este um mercado em ascensão, mesmo em períodos de crise, ao consolidar a relação mercantil da educação privada, tornando as IES em "fábricas de diploma" como apresenta Bittar (2002).

Com o saldo de um 10895 milhão, oitocentos e noventa e cinco mil contratos, entre 2010 e 2014, o FIES mantém muitas IES privadas a partir de investimento do Estado. Como exemplo, o MEC/FNDE aponta o gasto com FIES no ano de 2014, chegando à casa dos 13 (treze) bilhões de reais. Percebe-se, então, o aumento exacerbado da projeção de crescimento de financiamento estudantil, fundamentando-se nos mitos apresentados anteriormente e reforçando a precarização do serviço público. Tal opção acaba por acentuar o crescente investimento do Estado em grandes instituições privadas.

Cabe refletir sobre a consolidação e o reforço do Estado brasileiro como Estado Mínimo, pois ao invés de investir na ampliação do ensino superior público e gratuito, investe-se intensamente em instituições privadas, passando para o mercado privado a sua função de oferta deste nível de educação, criando-se uma falsa sensação "inclusão".

Nesse sentido, Leher $(2015$, p. 35) apresenta os seguintes questionamentos: "Que significa subordinar a formação da juventude às instituições financeiras? Que consequências podem advir do fato de que as instituições financeiras controlam as instituições privadas de ensino? (...) qual é o negócio? É o ensino ou a instituição financeira?". Para Silva e Souza $(2017$, p. 2) tal educação institucionalizada e privatizada acaba por ter papel de formar mão-de-obra adestrada para o mercado de trabalho, a qual se resume "ao papel de fornecer mão-de-obra qualificada ao setor produtivo em expansão, como se $\mathrm{o}$ ato de educar fosse uma ação extensiva à máquina".

Assim, a educação se torna um bom negócio para os investidores. Mesmo sendo uma das principais bandeiras dos Governos Lula/Dilma, a inserção de brasileiros na 
faculdade (LEHER, 2015), não tem garantido a qualidade do ensino ofertado por estas instituições. Isso porque nas IES privadas pouco se tem espaço para atividades reflexivas, de pesquisa e extensão, por uma razão simples: essas atividades não são essenciais às necessidades do mercado. Leher $(2015$, p. 37) afirma ainda que "é preciso refletir muito sobre o sentido da mercantilização atual, que altera tanto as universidades públicas quanto as universidades privadas mercantis". Para o autor tal fenômeno contribui apenas para consolidação do novo mercado em ascensão.

\section{Procedimentos MetOdológicos}

Esta pesquisa é um estudo qualitativo, cuja abordagem interpretativa (Coutinho, 2011) busca investigar o objeto, a saber, a mercantilização do Ensino Superior no contexto das políticas afirmativas. $O$ estudo apresenta as relações entre a teoria e a prática sem generalizações, com análise das categorias que emergem da pesquisa com estudantes, a fim de compreender o fenômeno das políticas do FIES e PROUNI, respondendo ao objetivo do estudo, que é analisar o fenômeno da mercantilização do Ensino Superior Brasileiro no contexto das políticas afirmativas.

Para análise dos dados, a pesquisa foi realizada com metodologia qualitativa, a partir de estudo de caso (YIN, 2010), com a recolha de dados por meio do instrumento entrevista semi-estruturada -, com os eixos: caraterização do estudante, perfil de acesso, formação da família, proposta pedagógica e curricular, mercado de trabalho, acesso à formação superior, contradições e avanços na educação.

A pesquisa estruturou sua busca de dados pela amostragem casual, mas com o público participante dos sistemas de financiamento da IES privadas, selecionadas de acordo com a aceitação de participação do estudo. Essa amostra tem o perfil de ambos os sexos, de qualquer idade, com estudantes provenientes do município de Icó-CE. A instituição oferta oito (8) cursos de graduação e conta com aproximadamente 5 mil alunos, no ano de 2016. Desses alunos, cerca de 70\% mantém contrato com o Programa Universidade para Todos - PROUNI e através do Fundo de Financiamento Estudantil- FIES, alvo desta investigação.

Com um banco de dados de 197 alunos no curso de serviço social, filtramos os que participam de programas de financiamento, com um total de 158: 41 alunos do PROUNI e 117 com suporte do FIES. Diante da viabilidade da amostra para um estudo qualitativo, tivemos 15 respondentes neste estudo de caso.

\section{RESULTADOS E ANÁLISE DOS DADOS}

Evidenciamos como objetivo do estudo a análise do fenômeno da mercantilização do Ensino Superior Brasileiro no contexto das políticas afirmativas, especificamente, FIES e PROUNI. O estudo de caso, desenvolve a análise de conteúdo com base nos estudos de Bardin (1997), de forma exploratória, em três momentos: 1. Préanálise dos textos das entrevistas, com a organização das respostas por tipo de financiamento; 2. Exploração do material, com as categorias: realidade social, o acesso ao ensino superior, facilidade/dificuldade do financiamento; entrada e qualificação para o 
SOUZA, K. P. de SANTOS, N. L.; SILVA, R. dos S. da

mercado de trabalho; 3 . Tratamento dos resultados, ocasião em que pudemos interpretar o grande impacto das políticas de ações afirmativas de forma direta na vida dos estudantes. Encontra-se o cruzamento das categorias do acesso ao ensino superior e qualificação para o mercado de trabalho, evidenciadas por $100 \%$ dos respondentes, ancoradas no estudo teórico sobre mercantilização da educação, alinhado aos teóricos apresentados (MARX, 1989; FREIRE, 1997; MÉSZAROS, 2008, MARTINELLI, 2008; LIMA, 2012).

Para caracterizar o contexto social dos estudantes do curso de Serviço Social, de Instituição de Ensino Superior Privada, localizada na região do Vale Central do Ceará, mais precisamente no município de Icó, somente possuem vivência de acesso e permanência na graduação por meio do FIES e PROUNI. Das 15 entrevistas realizadas (4 alunos com PROUNI e 11 com FIES) foi possível observar a vivência e a realidade com a qual irão se deparar enquanto profissionais. Segundo a pesquisa, o financiamento estudantil e as bolsas estudantis foram a chave para ingressarem no ensino superior, onde foi apresentado a eles perspectivas de futuro e amplas possibilidades de crescimento no mundo do trabalho, e vislumbram essas possibilidades de superação também para os usuários das políticas públicas que já começaram a lidar no campo de estágio, e que logo encontrarão a prática profissional. Salienta-se ainda que o público pesquisado não percebe a educação como mercadoria, e nem a si mesmo nesse processo da lógica mercantilista, como consumidor ativo do mercado da educação.

Tem-se que, dos 15 estudantes que participam desse estudo de caso, 10 (dez) acessaram o ensino superior através do FIES, destes, 1 (um) com financiamento de 50\%, 2 (dois) com financiamento de $75 \%$ e 7 (sete) com financiamento de 100\%. Entre aqueles, que acessaram através do PROUNI 5 (cinco) alunos possuem bolsas de $100 \%$.

Quanto ao perfil socioeconômico dos 15 alunos participantes da pesquisa temse que $93 \%$ estão entre 20 e 35 anos, e a composição familiar aponta que $70 \%$ dos pais, responsáveis, ou cônjuges dos entrevistados possuíam baixa escolaridade, não ultrapassando o nível fundamental, enquanto os outros 30\% variavam entre nível médio e superior incompletos. Quanto à renda familiar, $9(60 \%)$ possuem renda per capita média entre 200,00 e 600,00 reais, e os outros $40 \%$, renda entre 601,00 e 1.500,00 reais. Dessa forma, $80 \%$ se enquadra, segundo o IBGE (2018), como pertencentes a famílias pobres.

É valoroso compreender que as IES privadas surgem como alternativa onde o Ensino Superior Público não chega, possibilitando a mudança da realidade social de uma grande massa populacional e potencialmente produtiva. Reflete-se, assim, que a expansão massiva dos últimos anos das instituições de ensino superior privadas está diretamente atrelada a incentivos governamentais e às políticas de inclusão afirmativas aqui apresentadas, sendo uma evidente característica da própria política do Estado Mínimo neoliberal, segundo o qual o Estado se isenta de ofertar o serviço e paga para que o público tenha acesso a instituições privadas, repassando responsabilidades e investindo no grande capital. Porém, é salutar constatar que tal ação se reflete diretamente e de forma bastante impactante na vida dos cidadãos, principalmente jovens, provenientes de classes menos favorecidas e por vezes sem perspectiva de vida, devido à falta de oportunidades do seu ambiente de vivência.

É nítido, portanto, que o jovem pobre, morador de cidades interioranas, muitas vezes tendo concluído o ensino básico de forma precária, devido às más condições das escolas públicas, não seria concorrência para a classe média e classe média alta que 
conquistam as vagas nas universidades públicas do Ceará e do Brasil como um todo. Conclui-se que, a conjuntura atual não apresenta perspectivas de mudanças sociais reais (igualdade social). O FIES e o PROUNI apresentam-se como políticas de inclusão afirmativa de fato, o que não justifica a falta de investimento nas Universidades Públicas, e consolidase cada vez mais algumas características pertinentes às políticas públicas contemporâneas, como já apresentava Mota (2010), como um tendência recente, que seria a regressão de políticas redistributivas de essência pública e garantidora de direitos em detrimento de políticas de caráter compensatório de combate à pobreza, embora de caráter seletivo e temporário, sendo exatamente nessa perspectiva que se consolidam as políticas de inclusão afirmativas.

De acordo com a categorização das falas dos entrevistados, essas revelam que não houve grandes dificuldades aparentes no acesso ao financiamento estudantil. O que tem aparecido de maneira recorrente são as dificuldades de renovação de matrículas pelo FIES nos últimos semestres. Isso ocorre em função da dívida do MEC com os bancos, e de forma recente, das dificuldades para consolidação de novos contratos.

\title{
ANÁLISE QUALITATIVA
}

Para compreender a visão dos alunos sobre as ações afirmativas, FIES e PROUNI, foram realizadas entrevistas por um formulário contendo 20 (vinte) questões, com intuito de identificar experiências e impressões do ensino superior, da instituição privada e dessas ações afirmativas.

Quando questionados sobre como enxergavam a si, como cidadão formado com nível superior?

\begin{abstract}
Me vejo como uma cidadã que além do acréscimo intelectual que o nível superior nos proporciona, poderá ter acesso a melhores condições de trabalho, remuneração e consequentemente de vida, partindo do pressuposto de que o estudo e a qualificação é algo extremamente importante para que o sujeito se destaque como profissional e tenha melhores oportunidades no mercado de trabalho atualmente (Aluno 01).
\end{abstract}

Realizado e com uma boa remuneração (Aluno 14).

Percebe-se também o sentimento de realização pessoal e profissional. Para muitos, a utopia de cursar o ensino superior torna-se realidade, desabrochando realizações não apenas de indivíduos particulares, mas de famílias inteiras. Muitos destes alunos são os primeiros de suas famílias a cursarem o ensino superior.

Os alunos foram questionados também acerca do seu novo papel social enquanto profissional formado, visando compreender a visão que estes possuem do mercado, e da relevância social da profissão escolhida, no caso, Serviço Social.

Contribuir, com ética, para a sociedade, principalmente se tratando da transformação da realidade social (Aluno 03). 
SOUZA, K. P. de SANTOS, N. L.; SILVA, R. dos S. da

Estar apta para exercer com veemência a missão da qual me foi incumbida como agente de direito em poder levar as pessoas menos favorecidas a mediação dos seus direitos enquanto cidadãos (Aluno 07).

Atuar como profissional em minha área com ética e profissionalismo (Aluno 11).

Assim, a perspectiva do exercício profissional dos alunos gira em torno da ética, do comprometimento ético e compreensão da realidade social. As falas acima representam as principais abordagens das demais. Vale salientar que esses eixos fundamentam o projeto ético-político do serviço social (NETTO, 2001), que tem como direcionamento a luta pela garantia do direito do cidadão e o compromisso ético.

Quando questionados sobre a ampliação das possibilidades de entrada no mercado de trabalho através do nível superior, as reflexões foram unânimes na compreensão: todos responderam "sim".

Com o nível superior é sim bem mais fácil de se encaixar no mercado de trabalho, porém o sistema em que nos encontramos inseridos, só isso não basta, ele requer que nos moldemos cada vez mais, como por exemplo não só a graduação, mas também uma especialização no mínimo (Aluno 02).

Sim, pois o mercado de trabalho está cada vez mais em busca de profissionais qualificados, hoje é muito difícil arrumar emprego só com o ensino médio, ou até mesmo com a graduação, pois existe um exército de reserva muito grande em quase todas as áreas. Porém com o ensino superior fica mais fácil, basta que você seja um excelente profissional (Aluno 09).

A essência das respostas dos alunos, perpassa o afunilamento do mercado para mão-de-obra mais qualificada e especializada, compreendendo que apenas o nível superior não é suficiente para entrar e permanecer no mercado. Como apresenta Mota (2010), o mercado necessita daqueles profissionais multifuncionais, que façam para além de suas funções "obrigatórias", sendo essa uma característica do Estado Neoliberal, como já apresentado anteriormente.

Reforçando os questionamentos anteriores, foi perguntado aos alunos qual a importância do ensino superior para suas vidas. Como resposta, obteve-se as seguintes percepções:

Ter a oportunidade de cursar o ensino superior representa uma realização pessoal e também familiar. Visto que meus pais não tiveram essa oportunidade devido questões financeiras. Estar prestes a concluir o ensino superior será a realização de um sonho deles e principalmente meu que através do meu estudo poderei alcançar oportunidades que ambos não conseguiram (Aluno 01).

A de mudança de vida, tanto economicamente como socialmente (Aluno 04). 
O ensino superior me despertou sonhos, vontade de almejar espaços, e a oportunidade de com a graduação propor qualidade de vida para minha família (Aluno 13).

A importância principal apresentada pelos alunos, retrata o ensino superior como a realização de um sonho ou de uma realização pessoal e familiar. Associando aos dados apresentados anteriormente, esse dado está ligado à baixa escolaridade dos pais/responsáveis/cônjuges. Assim, a "conquista" do acesso ao ensino superior passa de um mérito pessoal para um mérito coletivo. Continuando a reflexão sobre o acesso ao ensino superior, pediu-se aos entrevistados que listassem pontos positivos e negativos no modo como eles tiveram acesso ao ensino superior.

Acredito que o acesso ao ensino superior tem se tornado cada vez mais fácil devido a programas como o PROUNI e o FIES que proporcionaram mais facilidade à pessoas que em teoria não teriam condições de arcar com os custos de uma faculdade e dispunham de ensinos fragilizados ofertados pelas escolas públicas dificultando o acesso à universidades públicas amplamente concorridas. As novas modalidades de ensino como faculdades $E A D$, de fins de semana e semipresenciais também se apresentam como facilitadores desse acesso em regiões que não dispõe de instituições que ofertam o ensino superior e até mesmo para pessoas que não teriam tempo de cursar um ensino superior presencialmente (Aluno 01).

Os aspectos positivos são que com o ensino superior abre um leque de oportunidades no mercado de trabalho. Posso conseguir um emprego melhor do que o que já tenho, luto por isso todos os dias, quando terminar a graduação procurar fazer logo uma pósgraduação, pois a maioria dos concursos exigem prova de títulos e eu preciso está preparada para o mercado de trabalho. E o ponto negativo é que vou passar muito tempo pagando o curso (risos) (Aluno 09).

Positivos: consegui e FIES pois sem ele não iria conseguir pagar a faculdade

Negativos: consegui o FIES porém vou ter que pagar a dívida enorme ao governo (Aluno 12).

Como pontos positivos, aparecem de forma recorrente entre as respostas dos alunos a ampliação do acesso ao nível superior para todas as classes sociais e em várias modalidades de ensino, desde ações afirmativas como o FIES e o PROUNI, o próprio REUNI que interiorizou as instituições federais de ensino superior, e ainda a expansão de instituições ofertantes do ensino superior à distância (EAD). Como ponto negativo, aparece um de forma ainda mais recorrente, principalmente pela parcela dos entrevistados que fazem uso do financiamento estudantil, a dívida gerada após o termino de graduação e o medo de não serem inserido no mercado de trabalho, e, consequentemente a não quitação da dívida. 
SOUZA, K. P. de SANTOS, N. L.; SILVA, R. dos S. da

Quando os entrevistados foram questionados sobre a possibilidade de fazer faculdade fora da sua cidade ou região, a grande maioria, 12 dos 15 entrevistados, afirmaram que sim, porém salienta-se que, dos 15 entrevistados, apenas 6 residem na cidade de Icó, onde localiza-se a IES privada onde que foi realizada a pesquisa. Em nenhum momento questionam a necessidade de uma instituição pública para atendimento da formação na localidade.

Acredito que sim. Tudo depende da oportunidade que temos e agarramos, se eu não tivesse essa oportunidade de cursar um ensino superior a poucos quilômetros com certeza eu iria buscar outras oportunidades para contribuir no meu desenvolvimento pessoal e profissional (Aluno 10).

Aqueles que apresentaram o "sim"' como resposta, justificaram pela necessidade de buscar conhecimento, pela realização de um sonho, ou pela qualificação para o mercado de trabalho. Mas "sim", teriam o dispêndio, como ( 9 entrevistados) já o têm, de se deslocar até $140 \mathrm{~km}$ por dia para cursar o nível superior desejado. Questiona-se, então, sobre o que levou à visualização do acesso ao Ensino Superior como uma oportunidade real, já que a maioria dos entrevistados não possuíam perspectivas de acessar a graduação.

Sem dúvidas o PROUNI teve grande parcela na concretização dessa oportunidade. Sem ele, provavelmente teria tido grandes dificuldades no acesso ao ensino superior. Primeiro porque tive meu ensino em sua maioria concretizado em escolas públicas, a qual eu reconheço que me traria grandes desvantagens na conquista de uma vaga em uma instituição pública. Segundo, porque sem ele não teria condições financeiras de arcar com as despesas que uma faculdade requer, ainda mais em outro município que demanda ainda mais gastos (Aluno 01).

A oportunidade de ingressar com o FIES, me garantido uma chance financeira de forma mais adequada ao meu momento financeiro (Aluno 15).

Através da fala dos entrevistados é possível perceber a criticidade na observância do sistema educacional desde tipo de ensino, tanto por tê-lo vivenciado, como também por reconhecer que o ensino básico ofertado pelo sistema público dificulta o acesso ao ensino superior público. Como apresenta Bourdieu (1998), mais uma vez predomina a "seleção natural" permeando a questão econômica. Assim, novamente reforça-se o caráter compensatório do FIES e do PROUNI, inserindo o ensino superior na lógica do Estado Mínimo muito bem argumentado por Martinelli (2010): ao sustentar as responsabilidades de investir no terceiro setor, o Estado tira de si, além da responsabilidade da prestação do serviço, todos os encargos e cobranças que vêm com ele. A reflexão dialoga com a fala apresentada pelo Aluno 12, como vê-se abaixo:

Porque se der algum problema aqui na faculdade, tipo, o ensino não for de qualidade ou até um problema comigo mesmo, não é atrás do governo que tá me bancando, que eu vou resolver. Vou é atrás da 
coordenadora ou do diretor da faculdade, porque eu não "tô" pagando, mas o governo tá pagando por mim. Se eu estudasse em uma universidade pública e o ensino não fosse de qualidade, iriamos cobrar do governo!

Na sequência, questionou-se ainda aos alunos sobre a oferta do Ensino Superior Público na sua cidade: se, ainda assim, cursariam o Ensino Superior Privado. As respostas relatadas pelos alunos apresentam alguns pontos interessantes a serem analisados, pois dos 15 (quinze) alunos, 8 (oito) afirmaram que optariam pela universidade pública, com justificativa de que, mesmo com financiamento ou bolsas de estudo, teriam dificuldades para arcar com algumas despesas provenientes das instituições privadas. Já 7 (sete) alunos afirmaram que, mesmo havendo a oferta do ensino superior público gratuito, ainda assim optariam por cursar a graduação em IES privadas, ou seja, esses alunos não compreenderam o processo de mercantilização, o que se ressalta nas falas são a precarização da IES públicas e suas greves.

Existe a oferta do ensino superior em uma instituição federal no meu município a qual não oferta cursos que despertem o meu interesse, $e$ por já ter vivenciado uma má experiência devido às greves nesta mesma instituição durante o ensino médio não foi uma opção considerável para mim (Aluno 01).

Na situação em que se encontra nosso país não. Pois as faculdades públicas estão sucateadas, os profissionais lutam pelos seus direitos e entram muito em greve e isso acaba prejudicando aos alunos (Aluno 09).

Ao passo que em alguns aspectos se percebe a predominância do pensamento crítico acerca do ensino, neste questionamento fica visível a fragilidade do que Marx (1989) apresenta como identidade e luta de classes, ou seja, desde que o sujeito particular consiga $\mathrm{o}$ acesso a bens e serviços, $\mathrm{o}$ acesso da coletividade deixa de ser importante.

Além disso, percebe-se ainda o enraizamento de valores neoliberais na fala dos entrevistados, na crença do sucateamento público. A teoria de Viana (2012), que apresenta os "mitos" implantados pela ideologia dominante, ajuda e reforça o desmonte das políticas sociais, assim como é o caso da educação, no qual o próprio Estado reforça esse sucateamento como algo fatídico e inevitável. Apresenta, ainda, Mota (2010), a precarização como algo inexorável, sendo tomada como algo impossível de ser superado, isso no tocante às políticas públicas.

Os entrevistados foram questionados acerca da qualidade do ensino, se esse é compatível com sua expectativa. Quatorze outros alunos afirmaram que "sim", inclusive apontando para a superação das expectativas.

Ao meu ver, todas as instituições de ensino apresentam suas vantagens e desvantagens, suas facilidades e suas dificuldades. $O$ ensino superior da instituição privada não é diferente. Entretanto, apesar das dificuldades comuns em todos os ambientes de ensino, 
SOUZA, K. P. de SANTOS, N. L.; SILVA, R. dos S. da

considero sim o ensino na rede privada do ensino superior de qualidade de acordo com a experiência que estou vivenciando, inclusive superou as expectativas criadas (Aluno 01).

Sim. Embora a instituição por ser privada não permita uma abertura maior para intervenções (Aluno 03).

Ao passo que se percebe nas falas dos alunos a "preferência" pelo ensino superior privado, devido ao sucateamento do sistema público de ensino de uma maneira geral, há receio dos mesmos com relação à qualidade do ensino ofertada pelas instituições privadas, percebendo-se, então, uma relação contraditória nos discursos dos alunos. Já com relação ao quadro docente da instituição privada, foi questionado aos alunos se os professores possuíam competência técnica para suprir suas necessidades enquanto discentes.

As respostas apresentadas pelos entrevistados foram unânimes. Para eles todos os professores apresentam a competência técnica para estar à frente das disciplinas e para repassar seus conhecimentos, embora com algumas ressalvas relacionadas à atualização de métodos de ensino.

Foram questionados ainda sobre a estrutura física da instituição, e suas referências foram o sucateamento das IES públicas.

Sim. A instituição tem disposto de todas as ferramentas necessárias para a realização de uma boa experiência estudantil, indo desde o auxílio da tecnologia nas aulas, climatização de salas, materiais, acervo bibliográfico até a disponibilização de espaço para desenvolvimento das atividades (Aluno 01).

A capacidade estrutural é uma das melhores que já pude conhecer. (Aluno 02).

Coube questionar também ao alunado se a proposta pedagógica e curricular é contextualizada em relação ao desafio da região. Do total dos entrevistados, 3 (três) apontaram que não estaria de acordo, e 12 (doze) que sim.

Ao meu ver, a proposta tem mostrado uma grande preocupação em qualificar o aluno para a profissão como um todo. Os desafios abordados são muito mais relacionados à nível nacional. Em relação às dificuldades regionais, vejo pouca abordagem (Aluno 01).

Sim, uma vez que toda a teoria abordada em sala de aula condiz com a prática profissional percebi isso durante o estágio do curso (Aluno 09).

Como foi aderir ao FIES? Salienta-se que, na época do acesso desses alunos, o processo burocrático era um pouco diferente do que é hoje, já que todos os entrevistados cursam entre $6^{\circ}$ e $8^{\circ}$ semestres. Assim, as respostas dos entrevistados seguiram a seguinte linha: 
Fácil meu processo foi simplificado, não precisou de avalista (Aluno 04).

Foi simples, fiz minha inscrição no site do MEC e depois fui até ao Banco do Brasil com dois fiadores. Não teve burocracia como hoje está tendo. Só consegui 75\% por que eu já trabalhava e meu esposo também (Aluno 09).

Algumas pessoas me orientaram a "essa solução" já que eu não queria desistir de forma alguma da faculdade e por condições financeiras não tinha condições de pagar, vendo o fies como solução (Aluno 10).

Assim, foi perguntado aos alunos entrevistados se, para eles, a educação é uma mercadoria. Para 7 (sete) entrevistados a educação não se caracteriza como mercadoria, já para 8 (oito) dos alunos, sim, a educação é considerada mercadoria.

Percebe-se uma compreensão muito positiva por parte dos alunos sobre o FIES e o PROUNI, o que é compreensível, já que essas ações possibilitaram suas entradas no Ensino Superior. Na mesma linha segue-se a pergunta: a possibilidade do financiamento estudantil foi determinante para seu acesso ao ensino superior? Para 14 dos 15 entrevistados, o financiamento e as bolsas do PROUNI foram determinantes para o acesso ao nível superior, a baixa renda dos alunos impossibilitaria o acesso ao ensino superior privado.

Sim, porque independente da mera ilusão que nos é posta, foi por meio desse financiamento que estou tendo a oportunidade cursar o ensino superior (Aluno 07).

Sem dúvida, pois sem esse financiamento seria impossível está concluído meu curso agora, pois além da mensalidade eu tenho que pagar o transporte, pois moro em uma cidade e estudo em outra. Mesmo sendo só $75 \%$ me ajudou bastante pois ficou mais acessível pagar só o restante, ou seja, os 25\% (Aluno 09).

Há clara tensão entre os estudantes que fazem uso do financiamento estudantil, de não conseguirem quitar a dívida acumulada ao longo dos anos de formação, devido às limitações do mercado de trabalho, e a percepção de que, a cada dia, o Exército Industrial de Reserva (EIR) aumenta, apesar de ser considerado pelos entrevistados, como já apresentado anteriormente, que a qualificação da graduação os possibilita mais chances de acesso ao mercado e a melhores remunerações.

Os entrevistados expuseram sua opinião a respeito de qual papel da educação superior viria primeiro: formação para a vida, ou a formação para o mercado de trabalho? Dos 15 alunos, apenas 4 (quatro) afirmaram a principal função do ensino superior seria a formação para a vida. 
SOUZA, K. P. de; SANTOS, N. L.; SILVA, R. dos S. da

Formar para a vida vem primeiro; tudo que aprendemos dentro da sala de aula irá refletir do lado de fora dela, quando estivermos nocampo de atuação, ali será colocada à prova se o que aprendemos realmente fez um efeito positivo ou negativo; contudo, caberá ao profissional se ele esteve mais concentrado no que o professor explicava (Aluno 07).

Já os demais acreditam que o processo de formação proposto pelo ensino superior seja de formar para o mercado de trabalho, pois em grande parte das falas eles compreendem o ensino superior como uma qualificação para o mercado.

Formar para o mercado. Justamente porque o ato de "trabalhar" está ligado diretamente à qualidade de vida. $O$ ensino superior tem a função de capacitar pessoas para que essas ingressem no mercado de trabalho e gerem renda e contribuições para o país (Aluno 01).

Capacitar para o mercado de trabalho, existem milhões de pessoas desempregadas, por não serem capacitadas. Hoje só o ensino superior não é mais suficiente para você se estabilizar em um emprego (Aluno 09).

A visão que os alunos possuem do ensino superior gira prioritariamente em torno do processo de formação e qualificação para o mercado de trabalho. Compreende-se essa a visão majoritária dos entrevistados, que utiliza como marketing principal a questão da empregabilidade.

Os participantes da pesquisa foram abordados ainda sobre contradições e avanços significativos que a Educação superior possibilita para a sociedade local. Eis o que depreenderam:

O ensino superior sem dúvidas proporciona avanços, não sei se exatamente na localidade onde me encontro. Por vezes enxergo o ensino superior como um preparador para o trabalho nas grandes cidades, tendo em vista as poucas oportunidades de emprego no interior. Ou seja, muitos interioranos após a formação buscam trabalho em outras localidades, o que acaba por não proporcionar mudanças significativas na localidade de origem do aluno (Aluno 01).

Sim, pois é de grande importância termos em nossa cidade ou região faculdades sejam elas particulares ou federais; o que realmente a sociedade precisa são de jovens com opiniões próprias e não opiniões copiadas de grupos de redes sociais, seres pensantes e não alienados a partidos políticos ou sugestões midiáticas... Assim, tais atitudes inovadoras farão diferença em meio ao caos instalado com toda essa parafernália chamada tecnologia do Século XXI (Aluno 07).

Com certeza. Uma vez que um profissional capacitado dependendo de suas competências pode avançar em sua determinada área contribuindo na sociedade (Aluno 10). 
Nas falas dos sujeitos não percebemos as contradições de falta de investimento na área de educação pública, diante do fato de que cerca de $60 \%$ necessita se deslocar mais de $140 \mathrm{~km}$, pois não tem curso superior na sua localidade. Além desse aspecto da forte expansão do setor privado no interior do Ceará, demarca-se a secundarização de ser pública ou privada, e pode-se inferir que não percebem a mercantilização. $O$ que se evidencia é que $100 \%$ dos entrevistados atestam que o ensino superior afeta a realidade local, tornam-se mais pensantes e até capacitados para o mercado de trabalho, em um reconhecimento da faculdade/universidade como espaço de reflexão crítica e de rompimento com a alienação. Portanto, de forma direta, a sociedade é beneficiada sob vários ângulos.

\section{CONSIDERAÇÕES FINAIS}

Ao buscar a mercantilização do Ensino Superior Brasileiro no contexto de políticas afirmativas, nomeadamente o Fundo de Financiamento Estudantil - FIES e Programa Universidade para Todos - PROUNI, nas falas dos sujeitos percebeu-se avanços no impacto real destas políticas na vivência dos estudantes, e nas transformações de suas realidades por meio do dimensionamento do impacto econômico e social proporcionados pela oportunidade de acesso e interiorização no Ensino superior. Encontramos falas recorrentes dos pontos negativos, que demarcam a contradição quando reconhecem a questão do endividamento e o receio de não ser inserido no mercado de trabalho. O que se percebe é uma lacuna de compreensão sobre a falta de investimentos do Estado na modalidade pública, e na falta de oportunidades, sem demarcar a compreensão do redimensionamento do dinheiro público em instituições de Ensino Superior Privadas.

Todo esse contexto apresentado permite dizer que há aprofundamento da mercantilização da educação superior. Isso ocorre, dentre outras coisas, devido aos baixos investimentos do Estado nas IES públicas, e aos crescentes investimentos nas IES privadas. Tal movimento abre, a um só tempo, um espaço e consolida um novo mercado para o capital financeiro.

As políticas de ações afirmativas que permeiam a Educação Superior no Brasil apresentam-se, na atualidade, como alternativas de rompimento com o ciclo da pobreza. Vê-se que, no país, o acesso e o investimento nas Universidades Públicas são bastante limitados, devido à lógica neoliberal, tornando-se mais viável terceirizar o ensino do que responsabilizar-se por ele. Dessa forma, o governo investe todos os anos bilhões de reais em bolsas integrais e parciais no PROUNI e em Financiamento Estudantil (FIES), para que estudantes de classes menos favorecidas tenham acesso ao ensino superior, porém privado.

Na lógica do Estado Mínimo, essa configuração nada mais é do que a transferência de responsabilidades do público para o privado e o investimento no grande capital. Mas, em uma realidade que não apresenta perspectiva de mudanças, no sentido de estabelecer a igualdade social, o FIES e o PROUNI surgem como programas de inclusão afirmativa, pois "incluem" aqueles que não teriam acesso ao ensino superior no contexto social atual, desde condições socioeconômicas até condições sociais e geográficas, que impossibilitam, fragilizam ou dificultam esse acesso. 


\section{THE MERCANTILIZATION OF BRAZILIAN HIGHER EDUCATION: THE CONTRADICTIONS AND POSSIBLE ADVANCES IN THE CEARENSE REALITY}

ABSTRACT: The article discusses the complex scenario of financing higher education and researches the affirmative policies of Brazilian student finance. Thus, a study aims to analyze the phenomenon of the commercialization of Brazilian Higher Education, through affirmative policies: FIES and PROUNI. The study initially presents a brief historical review, of the relationship between education as a right / commodity and a field research, with a case study carried with students, students of Social Service of private HEl, located in the central brackland of Ceará, city of Icó, who accessed Higher Education through FIES and PROUNI. After analyzing the content of the interviews, we recognize the impact of such policies in a market context with a strong privatization process in Brazilian higher education, central brackland of Ceará.

KEYWORDS: Financing education, commercialization, FIES, PROUNI.

\section{LA MERCANTILIZACIÓN DE LA EDUCACIÓN SUPERIOR BRASILEÑA: LAS CONTRADICCIONES Y} POSIBLES AVANCES EN LA REALIDAD CEARENSE

RESUMEN: El artículo analiza el complejo escenario de financiación de la educación superior e investiga las políticas afirmativas de la financiación estudiantil brasileña. Así, un estudio tiene como objetivo analizar el fenómeno de la comercialización de la Educación Superior brasileña, a través de políticas afirmativas: FIES y PROUNI. Inicialmente, el estudio presenta una breve revisión histórica, de la relación entre la educación como un derecho / mercancía y una investigación de campo, estudio de caso, estudiantes del Servicio Social de IES privadas, ubicados en las tierras centrales de Ceará, ciudad de Icó, a quienes accedió Educación superior a través de FIES y PROUNI. Después de analizar el contenido de las entrevistas, reconocemos el impacto de tales políticas en un contexto de mercado con un fuerte proceso de privatización en la educación superior brasileña, tierras centrales do Ceará.

PALABRAS CLAVE: Financiacion educación. Comercialización. FIES. PROUNI.

\section{REFERÊNCIAS}

ANTUNES, R. Adeus ao trabalho?: ensaio sobre as metamorfoses e a centralidade do mundo do trabalho. 17 ed., São Paulo, Cortez, 2015.

BITTAR, M. Educação Superior - o "Vale-Tudo" na mercantilização do Ensino. Revista de estudos de Educação, Ano 04, n.2, novembro de 2002. 
BOURDIEU, P. A Escola conservadora: as desigualdades frente à escola e à cultura. In NOGUEIRA, M. A.; CATANI, A. (org.) Escritos de educação. 2. ed. Petrópolis, Rio de Janeiro: Vozes, 1998.

COUTINHO, C. Metodologia de Investigação em Ciências Sociais e Humanas. Teoria e Prática. Coimbra: Almedina, 2011.

FERREIRA, A.V. ; LUSTOSA, F. G. ; LIMA, M. C.; JUNIOR, M. M. V.; HOLANDA, P. H. C.; LIMA, T. M. B.; LACERDA, C. C. S. Precarização do Trabalho e Saúde dos docentes das Universidades Públicas Brasileiras. ADUFC. EDUece: 2015.

FREIRE, P. Pedagogia da autonomia: saberes necessários à prática educativa. São Paulo: Paz e Terra, 1997.

LEHER, R. Políticas Públicas de Educação Superior no Brasil. In: FERREIRA, A.V.; LUSTOSA, F. G.; LIMA, M. C.; JUNIOR, M. M. V.; HOLANDA, P. H. C.; LIMA, T. M. B.; LACERDA, C. C. S. Precarização do Trabalho e Saúde dos docentes das Universidades Públicas Brasileiras. ADUFC. EDUece: 2015.

LIMA, L. C. Aprender para ganhar, conhecer para competir: sobre a subordinação da educação na "sociedade da aprendizagem". São Paulo: Cortez, 2012 - Coleção questões da nossa época; v. 41.

MARTINELLI, M. L. Serviço Social: identidade e alienação. 15 ed. São Paulo: Cortez, 2010.

MARX, K. "Terceiro Manuscrito". In: Manuscritos econômicos-filosóficos. Lisboa, 70 ed., 1989. p. 229-235.

MÉSZAROS, I. A educação para além do capital. São Paulo: Boi Tempo Editorial, 2008 (Mundo do Trabalho).

MOTA, A. E. Seguridade Social Brasileira: Desenvolvimento Histórico e Tendências Recentes. MOTA (et. al) (orgs), 4 Ed. - São Paulo: Cortez; Brasília,DF: OPAS, OMS, Ministério da Saúde, 2009.

NETTO, J. P. A construção do Projeto Ético-Político do Serviço Social, Serviço Social e Saúde, Brasília, CFESS/ABEPSS/CEAD/UnB, 2001.

SILVA, R. S; SOUZA, K. P. (Des)envolvimento Educacional e profissionalização um debate visceral para o Coenvolvimento. Revista Amazônida: Revista do Programa de PósGraduação em Educação da Universidade Federal do Amazonas, v. 2, n. 1, p. 03-18, 2017. Disponível em:

http://periodicos.ufam.edu.br/index.php/amazonida/article/download/3695/3579/ Acessado em 10.09.2020. 
SOUZA, K. P. de SANTOS, N. L.; SILVA, R. dos S. da

SILVA, V. A. C. Políticas compensatórias. In: OLIVEIRA, D. A.; DUARTE, A. M. C.; VIEIRA, L. M. F. DICIONÁRIO: trabalho, profissão e condição docente. Belo Horizonte: UFMG/Faculdade de Educação, 2010. Disponível em: http://www.gestrado.org/pdf/325.pdf Acessado em: 20 abr. 2020.

SOUZA, C. Políticas Públicas: questões temáticas e de pesquisa. Disponível em: http://www.cadernocrh.ufba.br/viewarticle.php?id=273 Acessado em: 20 abr. 2020.

VIANNA, M. L. W. O Silencioso desmonte da Seguridade Social no Brasil. In: BRAVO, M. I. S.; PEREIRA, P. A. (org.). Política Social e Democracia. 5a Ed. - São Paulo: Cortez; Rio de Janeiro: UERJ, 2012.

YIN, R. K. Estudo de caso: planejamento e métodos. (4a ed). Porto Alegre: Bookman, 2010.

Karine PinhelRo de SouzA: Pós-doc em Ciências Socais, Políticas e do Território Universidade de Aveiro, Doutora em Ciências da Educação, especialidade em Tecnologia Educativa - Universidade do Minho/Portugal. Mestra em Políticas Públicas e Planejamento - UECE, Especialização Gestão Escolar - UECE e Informática Educativa-UFRGS, graduação em Letras pela Universidade Estadual do Ceará. Foi professora substituta da Universidade Federal do Ceará - UFC. Coordenou o Projeto Agentes Digitais(UFCVirtual), objeto de estudo no doutorado, foi pesquisadora visitante no Knowledge Media Institute (KMi) Open University - Reino Unido. Foi orientadora da Célula de Formação de Professores na Secretaria de Educação do Estado do Ceará - SEDUC - CE. Premiação na área de TIC, com o projeto RiverWalk Brasil, parceria com Universidade de Michigan, Edital Economia Criativa na categoria Formação para competências criativas - Ministério da Cultura.

Orcid: https://orcid.org/0000-0003-2727-7475

E-mail: kpinheiro.projetos@smail.com

Nayana Lima Santos: Possui graduação pela Universidade Estadual do Ceará (2009.2). Especialista em gestão Pública pela Universidade Estadual do Ceará (2012). Mestre em Ciências da Educação e Multidisciplinaridade pela Estácio de Sá. Mestranda em Serviço Social, Trabalho e Questão Social pela Universidade Estadual do Ceará (2018). Tem experiência como docente no curso de Serviço Social. Atualmente atua como Diretora Especial do Trabalho e Assistência Social - Município de Jaguaribe/Ceará.

Orcid: https://orcid.org/0000-0001-8561-8819

E-mail: nayanalimaas@gmail.com 
Rafael dos Santos da Silva: Possui graduação e mestrado em Administração. Cursa doutorado em Sociologia na Universidade de Coimbra - UC. Faz carreira no Magistério Superior lotado na Universidade Federal do Ceará. Tem experiência na área de Administração Pública, Sociologia e Docência. Contribui em vários movimentos sociais relacionados a violência, direitos humanos e combate a pobreza. Participa como convidado do grupo do Observatório de Políticas Públicas da UFC e do Observatório de Políticas Públicas do meio Rural da UFC. Concentra interesse nas seguintes áreas: desenvolvimento, pobreza (rural/urbana), distribuição de renda, cidades, violência.

Orcid: https://orcid.org/0000-0001-7015-5786

E-mail: cmarafael50@gmail.com

Este periódico utiliza a licença Creative Commons Attribution 3.0, para periódicos de acesso aberto (Open Archives Iniciative - OAI) 